\title{
O próprio do desejo: a emergência da diferença extensiva entre os viventes (Aikewara, Pará)
}

\author{
- Orlando Calheiros \\ Pontifícia Universidade Católica do Rio de Janeiro, Rio de Janeiro, \\ Rio de Janeiro, Brasil
}

\section{DOI 10.11606/issn.2316-9133.v24i24p487-504}

\begin{abstract}
resumo Para os Aikewara, povo Tupi-Guarani do sudeste do Pará, todo corpo tem o seu caminho (apé), algo que lhe é próprio, que o define de uma maneira profunda. Homem (akuma’é), ou mulher (kusó) é aquele que caminha enquanto tal, que percorre o caminho que é próprio desse tipo de corpo. Contudo, o caminho é menos um destino do que uma trilha que pouco a pouco se inscreve no seio da floresta, como diziam os próprios Aikewara: o caminho de um corpo não está dado e por isso mesmo pode ser desviado. O que se passa, portanto, quando um homem se desvia do caminho que lhe era próprio e "avança" como mulher? Isto é, o que acontece quando este se comporta como uma mulher? Com efeito, a finalidade deste texto é apresentar ao leitor o esboço de uma ontologia na qual, para todos os fins, um corpo pode vir a se tornar outro, em que um homem pode vir a se tornar efetivamente uma mulher e vice-versa. Para tanto, tomamos como exemplo a leitura que a filosofia aikewara faz do desejo.
\end{abstract}

palavras-chave Etnologia; Antropologia filosófica; Tupi-Guarani; Corpo; Gênero.

\section{About desire: the emergence of extensive differences among living ones (Aikewara, Pará)}

abstract Every kind of body has its own path, something that defines it in a profound way, says the Aikewara, Tupi-Guarani people from southwest Pará. For example, man or woman is the one who walks as man or woman, who walks through the path that belongs to this "kind" of body. However, the path of a being in particular is not given and, therefore, can be diverted - is more like a trail that is gradually drawn in the forest. That said, the question posed by this article is: What happens when a man strays from his own path and "walks" as a woman? In other words, the intent here is to present a outline of na ontology which, for all purposes, one body can turn out to be another, where a man can come to effectively become a woman, and vice versa.

keywords Ethnology; Ontology; Tupi-Guarani; Body; Gender 


\section{Preâmbulo}

It's no use going back to yesterday, because I was a different person then.

Lewis Carroll, Alice in Wonderland

Dizem os Aikewara1 que todo "vivente" (akówa’e) possui um "caminho/ trilha" (apé) que o define; melhor dito, todo vivente se define pela trilha que percorre. Com efeito, é homem, ou mulher, ou animal, todo aquele que caminha enquanto tal, todo aquele que percorre o caminho que é próprio dessa espécie, classe, sexo... etc. Ser gente, humano, por exemplo, corresponde a "agir/fazer" (apó) como gente, a "falar" (séeng) como gente, a dormir como gente (dormir em redes, dormir sempre à noite), a dançar como gente. Pressupóe, ainda - e isto segundo os próprios Aikewara -, um certo risco; ser gente, propriamente, pressupóe viver na eminência de deixar de sê-lo, pressupóe, por exemplo, buscar o contato ativo com os contrários - e todo contato implica sempre algum tipo de conflito, seja ele implícito ou explícito,$-{ }^{2}$ seja por meio da guerra, seja por meio da aliança - que, como se sabe, se trata de uma guerra por outras vias (cf. VIVEIROS DE CASTRO, 2002a; 2007). Voltaremos a esse ponto mais adiante, pois o que nos importa, ao menos por ora, é que aquilo que meus amigos chamam de "caminho" é menos um destino imutável do que uma trilha que pouco a pouco se inscreve no seio da floresta; que o caminho de um ser náo está dado e, por isso mesmo, pode ser desviado. Em outras palavras, nada garante que aqueles que nasceram em determinado caminho, aqueles que nasceram no caminho próprio dos humanos, por exemplo, permaneçam neste até o fim; que permaneçam humanos, em suma. E isso se aplica a todas as modulaçóes possíveis da vida. Até o momento, falamos de - na falta de uma palavra melhor - espécies naturais, mas poderíamos estar falando do sexo de um vivente qualquer.

Mas qual seria a relação entre esses diferentes aspectos da vida? Qual seria a relação entre o gênero e a taxonomia? Como resposta, os Aikewara se remeteriam àquilo que denominam em sua própria língua como putar - em português, "querer", “desejar” ou "gostar”. Explico: segundo meus amigos, o caminho ${ }^{3}$ de um vivente, qualquer que seja, é o desdobramento de seus desejos. A filosofia nativa é um tanto explícita quanto a isso: somos - nossos corpos são -, em todos os aspectos, em todas as modulações possíveis, uma consequência direta daquilo - ou daqueles - que desejamos e, ainda, da maneira como desejamos tais coisas ou seres (cf. CALHEIROS, 2014). Pressuposto que, me parece, o pensamento mítico leva até as últimas consequências, colocando o putar, o desejo, na origem de tudo o que hoje existe, a terra em que vivemos, inclusive. 
Assertiva que, até o momento, carece de algum fundamento etnográfico. Faz-se necessário, portanto, recorrer propriamente ao - coloquemos assim - núcleo do pensamento que lhe serve de sustento: em outras palavras, é necessário recorrer ao mito. ${ }^{4}$ Façamos, então, um breve sobrevoo sobre o pensamento mítico aikewara, mais especificamente, sobre alguns momentos cruciais de sua cosmogonia.

\section{O desejo destoante dos viventes}

Dizia-me Awasải, entáo o mais velho dos cantores aikewara, que antes dessa terra - isto é, antes desse mundo em que todos vivemos - existira outro, existira um mundo onde o céu era mais baixo, da altura de uma castanheira, onde não havia noite, onde não havia nem dor nem morte, pois os homens, como as cobras de hoje, apenas trocavam de pele e renasciam. Um mundo onde não existiam animais, pois, conforme sua esposa, $\mathrm{Mu}-$ retama, costumava repetir - traduzindo suas palavras para o português -, "ali não havia nada, só 'gente' (awa) e jabuti (Chelonoidis carbonaria)". Ao contrário do mundo em que vivemos, o mundo-de-outrora não era "duro" (otó), como me explicava a mesma Muretama, apontando para as linhas do segundo versículo do "Gênesis" - "[e] a terra era sem forma e vazia" - em um surrado exemplar da Bíblia, que carregava consigo para cima e para baixo. Contudo, "sem forma e vazia", alertava-me a própria, não significa que não houvesse nada nesse outro mundo - desde sempre, havia pessoas e jabutis, lembro -, talvez, apenas que ali não existiam diferenças (externas e mensuráveis) entre os seres, que ali não existiam "formas" estáveis; que ali existia apenas o "não marcado" da existência; em outras palavras, que ali só existia forma humana em sua condição mais básica. ${ }^{5}$

E isso não era bom, dizia-me, Awasải. Foi preciso que algo acontecesse, que algo rompesse o tênue equilíbrio do caosmos pré-cosmológico, para que as coisas do mundo, para que o próprio mundo tal qual o conhecemos hoje, pudessem vir a existir. O evento disruptivo, se assim podemos concebê-lo, foi o amadurecimento, o crescimento de Seneruw, o demiurgo que, por definiçáo, sempre existiu, alheio ao mundo dos "viventes" (akówa'e). A divindade cresceu e sua influência avançou sobre a superfície da primeira terra, expandiu-se sobre ela, contagiando-a, transformando-a de maneira profunda. ${ }^{6}$ Os corpos dos humanos de outrora se transformaram. Tocados pela influência do demiurgo, afetados, tornaram-se capazes, eles mesmos, de madurar, de crescer; antes "leves", tornaram-se cada vez mais "pesados", rígidos e estáveis; agora era possível envelhecer - ainda que não fosse possível morrer de velhice, detalhe importante. ${ }^{7}$ 
Contudo, por ora, o que nos importa é a maduração específica de um corpo, mais precisamente o corpo de uma mulher chamada Cutia. Conta-se que quando Cutia teve a sua menarca - talvez ela tenha sido a primeira, especulavam Awasa'i e Muretama -, as primeiras gotas de suas regras tocaram o solo e despertaram, assim, o desejo "destoante" (ohotehé) de um homem chamado Cobra. Desejo destoante, dizia-me o cantor, pois o cheiro das regras, sob condições normais de percepção, é dá ordem do "podre" (punura), ao passo que para Cobra era doce. Mais do que isso, o sangue, afirmam os Aikewara, é um potente depressor sexual: um homem cujo pênis entre em contato com o sangue menstrual se tornará irremediavelmente impotente, correndo o risco, inclusive, de apodrecer e ter que ser amputado. Contudo, como descrevi, o desejo de Cobra era destoante dos demais, o sangue, sobretudo seu cheiro, não apenas lhe era doce ( $e^{\prime} e \hat{)}$, como o deixava extremamente excitado, em todos os sentidos; "era como cachaça para ele", dizia-me Muretama.

Com efeito, excitado, Cobra pôs-se a cantar - coisa que os humanos-de-outrora não faziam -, dando início a uma estranha "dança-ritual” ( $p u$ rahai) cujo resultado foi a emergência das primeiras diferenças entre os seres: desses movimentos emergiram as cobras, as cotias, os pássaros e as mucuras. Esse foi o primeiro momento em que uma diferença extensível e mensurável entre os viventes se fez presente, ainda que ela náo tenha sido suficiente para instaurá-la de maneira definitiva no seio da humanidade-de-outrora - pois, ainda que se comportassem e parecessem com animais, estes que primeiro se diferenciaram dos demais humanos ainda podiam se comportar/parecer como/com "gente" ${ }^{8}$ Esse foi apenas - e este apenas é já um muito, sabemos - o primeiro de outros que, sucessivamente, operaram cortes cada vez mais profundos e definitivos no fluxo de consubstancialidade original entre os viventes.

Corte ainda mais profundo foi aquele que se originou - mais uma vez - da vontade, do gosto "destoante/anormal" de um homem conhecido apenas pelo epíteto Tukasa'sara (lit. Dono-da-tocaia), cujo resultado foi a cisão da primeira humanidade em duas metades. Tratava-se de um homem que trazia consigo um estranho "desejo", uma "fome" (ma'eway) pela carne de seus semelhantes. ${ }^{9}$ Conta-se que seu desejo era tanto, que o inspirou a construir uma tocaia e flechas especiais, o inspirou a, em suma, construir artefatos que lhe permitiriam consumir a carne destes que até então tomava por "parentes": ${ }^{10}$ diz-se que aqueles que eram tocados pelas flechas emitidas do interior da tocaia transformavam-se em mutuns (Cracidae sp.) - ao menos aos olhos daqueles que disparavam as flechas -, e eram consumidos como tal. Mas isso não é tudo, pois o próprio "dono da tocaia", conforme se servia da carne desses mutuns, também se transformava: conforme con- 
sumia seus antigos semelhantes, diferenciava-se de si mesmo, daquilo que fora outrora, tornando-se agora um awaeté, tornando-se agora "gente de verdade" - maneira como os próprios Aikewara se denominam. De fato, Tukasásara foi o percursor de uma nova espécie, o "dono" de um novo povo. Com o tempo, sua diferença, seu desejo destoante - e os Aikewara são um tanto explícitos quanto a isto -, contagiou outros, propagou-se no seio da humanidade de outrora, modificando-a, divindindo-a. A humanidade imatura e indivisa de outrora deu, então, passagem a uma humanidade dividida entre "gente de verdade", os contagiados pelo desejo do dono-da-tocaia, e aqueles que lhes serviam de alimento, os mutuns.

O mito nos coloca, assim, dois problemas que se mostram complementares: o primeiro deles diz respeito à origem das unidades discretas, dos diferentes tipos de seres que hoje habitam o mundo. Com efeito, pois, se olharmos com cuidado para a cosmogonia aikewara, notaremos que os seres que hoje existem no mundo náo surgiram todos de uma única vez. Perceberemos que para cada tipo de bicho ou gente foi necessário um que chamam de "primeiro-desencadeador" (hypia), como o Tukasa'sara, um que primeiro se tornou tal coisa, que "madurou" dessa forma, isto é, o primeiro que trilhou determinado caminho, diferenciando-se dos demais. ${ }^{11}$ Tudo se passa como se esse movimento de diferenciação não operasse apenas na promoção de movimentos intestinos - uma certa definição capaz de dotar um corpo de um contorno distintivo -, mas também na produção de uma certa capacidade de influenciar outros. De fato, todo corpo, alguns mais do que outros, dizem os Aikewara, é capaz de atrair outros para o seu entorno e, nesse processo, imbuí-los de seu próprio crescimento diferenciado. Em outras palavras, poderíamos dizer que a cosmogonia aikewara náo descreve tấo somente a origem dos diferentes tipos de seres que hoje habitam o cosmos, não descreve apenas a origem de seus corpos diferenciados, mas a forma como estes corpos se tornaram replicáveis em larga escala.

O segundo problema é o de que os mutuns existiam táo somente na perspectiva daqueles que desejavam devorá-los, isto é, na perspectiva daqueles que desejavam sua carne, pois aos seus próprios olhos ainda permaneciam humanos. Não pretendo, aqui, me deter sobre a celebérrima "qualidade perspectivista do pensamento ameríndio" (LIMA, 1996; VIVEIROS DE CASTRO, 1996), tocarei apenas naquilo que nos permitirá avançar: a noção de que a transformaçáo observada no mito, apesar de esta se remeter a tão somente um dos polos da relação, não tem nada de ilusória. Como já se observou em outras ocasióes, a qualidade perspectiva do pensamento ameríndio não reafirma a formulaçáo culturalista/naturalista segundo a qual uma Coisa-em-si é parcialmente apreendida por diferentes sujeitos (humanos, animais, espíritos... etc.). O pensamento ameríndio, 
como um breve sobrevoo pela literatura pode demonstrar, propóe a existência de uma multinatureza povoada por multiplicidades imediatamente relacionais (cf. GOLDMAN, 1975; VIVEIROS DE CASTRO, 2008). Destarte, o mito nos fala não de pessoas que são percebidas por outras como mutuns, mas da emergência de multiplicidades humanos-mutuns.

Isso posto, podemos avançar para o terceiro episódio, justamente aquele que encerra o plano mítico; aquele que poderíamos chamar de o mito da origem da sociedade aikewara. Aqui somos apresentados a um homem incapaz de suprir seus desejos alimentares, um caçador inepto, que, após um dilúvio, se transforma no último sobrevivente de seu povo. $\mathrm{O}$ mito avança, e o homem, em meio a uma busca incessante por outros humanos, se depara com duas aves, garça e mutum; duas aves que para si mesmas eram mulheres. Motivado pela solidão, este homem se recusa a disparar suas flechas sobre elas: ele as deseja como mulheres, como esposas, e é isso que elas se tornam para ele. Da união desse homem com a garça, diz-se, nasceu o primeiro chefe aikewara.

\section{O que se passou?}

Os mitos nos remetem a um mundo primevo onde "não existia nada", onde os viventes, ainda que atravessados por linhas de afinidade, ainda não se encontravam divididos em blocos molares de identidade interna, em espécies, classes... etc. Trata-se, como bem demonstrou Lévi-Strauss, de uma história do tempo em que os homens e os animais ainda não eram diferentes. E isso, como bem me dizia Awasa'i, não era bom. Com efeito, o pensamento mítico, sabemos, opera por meio de substituiçóes (sensu WAGNER, 1978), tudo se passa como se cada elemento, cada componente do mito, fosse posto apenas para ser substituído no momento seguinte. Os mitos em tela registram, justamente, a substituição gradual desse regime original, a emergência das diferenças extensivas entre os viventes: temos assim o primeiro "corte" no fluxo de consubstancialidade original e, consequência direta, a emergência dos primeiros animais; temos o registro de uma cisão profunda e a emergência daqueles que são "gente de verdade" (awaeté); por fim, temos o nascimento da própria sociedade aikewara. Cada um desses mitos gira no entorno do desejo destoante de um actante mítico: temos Cobra e sua estranha afeição ao sangue menstrual de uma moça; temos Tukasa'sára e sua fome; temos o caçador inepto que desejava as aves como esposas.

Em um pequeno experimento, poderíamos separar os mitos em dois grupos: de um lado estariam aqueles em que o desejo dos actantes promove uma disjunção (a origem dos primeiros animais), do outro, aqueles em 
que o desejo promove - se assim pudéssemos concebê-lo - uma síntese entre os viventes (a transformação das aves em mulheres). Nesse esquema inicial, o mito do Tukasa'sara estaria em ambos os polos, pois o desejo do actante promove não apenas a disjunção (a distinção entre ele, seu bando e suas presas), mas também uma conjunção, pois o seu desejo se espalha entre outros humanos, instituindo assim a emergência de um bloco molar de identidade, uma classe de seres, os awaeté. Essa distinção prematura nos permite, enfim, esboçar uma compreensão do desejo, a começar pelo seu sentido. Sentido, pois, como nos ensinam os mitos, o desejo dos viventes seria como a flecha lançada pelo caçador; ele, por definição, aponta na direção de algo: e esse algo é por definição o outro. A narrativa de Tukasa'sára nos oferece um desenho cristalino dessa proposição quando, por meio das flechas - que, por sua vez, são o desdobramento da fome do actante mítico -, traça uma linha demarcatória separando os caçadores de suas presas. Melhor seria dizer, traçando uma fronteira visível, extensiva, entre aqueles que desejavam como o Tukasa'sára, que desejavam a carne dos mutuns, e aqueles que, justamente, eram desejados e, por essa razão, vistos como mutuns.

Estamos aqui, como o leitor pode perceber, no campo clássico da comensabilidade e do canibalismo. Contudo, essa topologia inicial do desejo não me parece suficiente para compreender a aliança interespecífica presente no terceiro mito. A chave para o seu entendimento, creio, está na associaçáo entre o desejo e as flechas contidas no segundo e no terceiro mito. Começamos pelo fato de que essa associação ultrapassa os limites do pensamento mítico e alcança a esfera da vida cotidiana. Com efeito, as flechas têm fome, dizem os Aikewara. ${ }^{12}$ Elas não são meras ferramentas do desejo de seus possuidores, da sua fome; elas o incorporam, elas próprias desejam. E, ao contrário dos viventes, elas desejam de maneira indiscriminada: pela mira da flecha tudo, melhor, todos são comida - e por essa razão o seu manuseio e feitura são tão perigosos, interditos para crianças e mulheres.

No entanto, engana-se quem pensa que as flechas são capazes de promover uma disjunção absoluta entre aqueles que as lançam e seus alvos. Pelo contrário, diriam meus amigos, as flechas estabelecem uma relação profunda entre elas. E diriam isso baseados em um aspecto fundamental da existência, o de que toda ação implica uma reação na direção contrária, uma "vingança" (wepy). Destarte, para cada flecha disparada pelo caçador há uma flecha disparada pela presa, para cada flecha disparada há uma flecha recebida. No fim, o caçador, o predador, é também uma presa de suas presas. Estabelece-se assim uma relação entre os termos, caçador e presa, que se desdobra em uma zona de indiscernibilidade que deve ser dissipada por meio de uma série de interdiçóes e atividades subsequentes. ${ }^{13}$ 
Contudo, não me deterei sob os aspectos particulares dessas interdiçóes, não apenas por já tê-lo feito em trabalho de maior fôlego (CALHEIROS, 2014), mas pelo fato de que isso nos desviaria em demasia do objetivo deste texto. O que nos importa, ao menos por ora, é compreender que a flecha - e o desejo, lembro - estabelece uma relaçáo entre os termos, uma comunicação, e que esses termos, a exemplo dos actantes míticos, correspondem a multiplicidades (cf. VIVEIROS DE CASTRO, 1996; 2008). A flecha conecta a parte humana de uma certa multiplicidade à parte presa de outrem e vice-versa, a reversibilidade das posiçóes é fundamental.

Animais não são gente, repetiam os caçadores aikewara - em especial durante os preparativos para uma caçada -, e, por maior que seja o risco, são as flechas que garantem a manutenção dessa proposição. A alternativa, aprendi com os mesmos, seria pior, não flechá-los acarretaria uma identificação imediata com as presas, significaria aceder a sua perspectiva e tratá-las como gente, implicaria em deixar de desejá-las como comida; implicaria em desejá-las como amantes, em desejar como elas, em suma. As flechas, ao menos, oferecem a alternativa, uma possibilidade de sobrepujar a perspectiva desses outros, náo pela negação absoluta, mas pela via do comércio intempestivo. Náo se trata de simplesmente negar que esses outros viventes, os animais, são gente - isso seria uma grande tolice, segundo meus amigos -, trata-se de reafirmá-los enquanto animais, conectando-se a essa outra parte, a parte animal.

Tudo se passa, então, como no regime mítico, a começar pelo comércio estabelecido por meio da flecha entre Tukasa'sára e suas presas; sua fome (as flechas a incorporam, lembro) desdobra suas vítimas em mutuns, faz emergir nelas aquilo que existia apenas em potência, a parte presa desses viventes. $\mathrm{O}$ mito do caçador inepto nos mostra, justamente, o reverso dessa operação, aquilo que acontece quando um humano se recusa a disparar suas flechas na direção dos animais, quando se recusa a consumi-los - ou, para não sermos injustos com o personagem do mito, quando ele se mostra incapaz de fazê-lo: a conexão se efetua por outros meios, por via de suas partes humanas. E esse comércio que se estabelece entre semelhantes, ao menos entre membros de uma mesma espécie, nos coloca um problema complementar, o sexo.

\section{O homem que (quase) se transformou em mulher}

O que temos até então, a noção de que o desejo desenha uma topologia, uma linha demarcatória, distintiva, entre aquele que deseja e aquilo que ele deseja. Contudo, menos do que uma separaçáo radical, essa linha promove 
um comércio entre os termos - em geral, no momento da efetuação desse desejo. Até o momento, analisamos essa proposição sob a perspectiva das diferenças extensivas, da emergência das mesmas, que se inscrevem entre os diferentes tipos de viventes. Contudo, um dos mitos analisados nos propôs outro problema - e, contudo, aquele que talvez nos seja mais próximo -, o do papel do desejo durante o comércio entre membros da mesma espécie. Afinal, para que meu argumento a respeito do desejo seja válido, para que a investigação que empreendemos em busca de seu sentido tenha rendimento, é necessário que ele possa ser observado nesta esfera, digamos, íntima dos humanos. Para tanto, é mister que a esses três mitos acrescentemos um quarto, a história de homem-mulher conhecido apenas pelo epíteto ga'ipymonómonó-tara ("aquele-que-dá-demasiadamente-o-ânus").

Gäipymonómonó-tara era "um" que se fez "uma", um que, apesar de ter nascido homem, crescera como uma mulher (isto é, madurou como tal). Um que recusava sistematicamente as mulheres e mantinha relaçóes sexuais apenas com outros homens, homens que chamava de irmãos (-ru) - primos paralelos, provavelmente - e que a procuravam por ser uma exímia pintora corporal, coisa que, segundo meus amigos, "fazia melhor que as mulheres" - há, aqui, como o leitor pode imaginar, uma possível alusão aos seus dotes sexuais. Gäipymonómonó-tara era uma kusóangaw (lit. "mulher-simulacro" ou, na glosa nativa, "mulher-por-engano"), era "como os travestis de Marabá", diziam-me em bom português. ${ }^{14}$ Sucedeu-se que essa mulher-por-engano, de tanto fazer sexo com outros - "seu ânus era verdadeiramente insaciável", "sua fome náo acabava", diz o mito -, terminou engravidando de um de seus amantes. Uma gestação anormal, contam, pois a despeito de se parecer tanto com uma mulher - semelhança que aumentava conforme tomava outros como amantes -, ga'ipymonómonó-tara era imperfeita, seu útero não era como o das outras - sim, ele/ela tinha um e era "imprestável" (eká-ikatuéyme) - era verdadeiramente incapaz de "entregar uma pele verdadeira" aos influxos de seus amantes. O ponto, parece-me, é fundamental. Não que fosse incapaz de engravidar ou entregar ao feto um corpo propriamente humano, como ocorre nos casos de amores abomináveis (entre irmãos, entre humanos e animais), o seu impedimento era outro, era incapaz de imbuí-lo na diferença necessária, de aquecê-lo ao ponto de redobrá-lo: ele era incapaz de torná-lo diferente de seu pai. Gäipymonómonó-tara era capaz, apenas, de produzir clones de seus amantes. E isso - da perspectiva de uma cosmologia obcecada pela produção de diferenças (cf. CALHEIROS, 2014) - é uma abominação.

O fim de gảipymonómonó-tara não poderia ser outro: fora morto por um de seus amantes. ${ }^{15} \mathrm{O}$ assassino temia que a criança fosse sua (todos os amantes de ga'ipymonómonó-tara temiam, e não eram poucos), mas não 
por vergonha ou coisa do tipo, seu medo não era que os outros descobrissem que ele mantinha relaçóes com a kusóangaw. Até mesmo porque, ao que tudo indica, todos da aldeia sabiam quem eram os amantes da kusóangaw e náo havia qualquer conflito em relação a isso. Seu medo era outro. Diz-se que ele tinha raiva do não nascido - e os Aikewara eram explícitos a esse respeito -, deste que, até onde se pode supor, seria "idêntico" (irutehetehé) a ele - todos sentiam medo, mas só ele teve coragem de dar cabo da criança e de sua genitora. Tudo se passa como se a história de ga’ipymonómonó-tara nos oferecesse um episódio análogo - ainda que enfraquecido - ao da origem da cisão entre humanos e animais. Aqui, temos um actante que, como Cobra e tukasa'sara, carrega consigo um desejo "destoante", um desejo que volta sua atenção para aqueles que lhes são próximos e não para aqueles que lhe são imediatamente diferentes, um desejo sexual voltado para os homens - de maneira sintomática, homens que são seus primos paralelos - e que ignora as mulheres. Mais uma vez, o desejo destoante se desdobra em movimento, em sexo, e conforme é posto em prática, opera uma transformação. Ga’ipymonómonó-tara gradualmente se transforma em mulher, ganha seios e até mesmo um útero - ainda que se tratasse de um útero "imprestável”. Diz-se que, inclusive, se tivesse sobrevivido, poderia vir a desenvolver uma vagina: o mito é explícito quanto à emergência do órgão feminino, ao ponto de se deter minuciosamente sobre o gradativo desaparecimento do pênis de Ga’ipymonómonó-tara.

Se, nos dois primeiros mitos que analisamos, o desejo operou uma cisão radical entre os humanos, desdobrando-os à maneira de uma especiação, aqui ele distingue primos paralelos por meio do sexo. Aquele que "desejava pelo ânus", isto é - presumo com boa segurança -, o passivo sexual, se transforma em mulher, enquanto os demais, ativos sexuais, assumiam a posição de afins, amadurecendo no processo. E digo tal coisa baseado em um detalhe náo revelado sobre o mito, o fato de que muitos dos amantes de ga’ipymonómonó-tara eram jovens que o procuravam, justamente, para aprender a fazer sexo e, assim, madurar propriamente como "homens de verdade", como "homens maduros" capazes de, posteriormente, constituírem famílias. "Homem de verdade", "homem maduro", glosas nativas de um mesmo termo, awaeté. Deparamo-nos, assim, com a lógica estabelecida no mito de Tukasa'sára, mas agora sob a perspectiva daquele que é desejado pelos awaeté.

\section{A origem das mulheres-por-engano e dos homens de verdade}

O mito, já dissemos, determina as condiçóes intensivas do sistema. Nesse caso, determina as condiçóes pelas quais os corpos podem ser trans- 
formados, nos diz como foi possível que os animais emergissem, justamente, do seio da humanidade de outrora; e como essa mesma humanidade se transformou em outra coisa, os homens se transformaram em awaeté. Mais do que isso, determina que tais condiçóes, de certa forma, ainda permanecem disponíveis; a metamorfose corporal, típica do regime mítico, permanece enquanto uma possibilidade real para os viventes, para seus corpos - ainda que sua intensidade seja pálida se comparada à do mundo-de-outrora.

Com efeito, afirmam os Aikewara que todo "vivente" (aköewa'e) tem um "caminho", uma "trilha" (apè). Dizem, por exemplo, que "gente/humano" (awa) é aquele que caminha como tal, e isso pressupóe que sinta "desejo" pelas coisas certas: pressupóe que, entre outras coisas, quando tenha "fome", sinta desejo pela carne de animais - e não pela carne de outros humanos. E que o leitor náo pense que se trata de um dado da existência; au contraire, trata-se de um desejo que começa ainda na gestação, quando os pais o "acostumam" a comer da carne dos animais, de preferência queixada (a presa humana por excelência). O influxo que se desdobrará em feto é, na origem, um ser canibal, tanto que ele se aloja no útero atraído pelo cheiro do sangue materno. É, portanto, fundamental que ele seja alimentado de maneira adequada, o que ocorre por meio da ingestáo do esperma masculino - que, por sua vez, é produzido pela ingestão de carnes, sobretudo, carnes de caça.

O processo visa garantir que, ao menos no momento do parto, o feto seja um humano. "Ao menos no momento do parto", digo, pois a "humanização" desse novo ser não cessa no nascimento. É preciso que continuem a acostumá-lo, primeiro pela ingestão do leite materno, que, como o esperma, é produzido pela ingestão de carne de caça, e posteriormente pela ingestáo de carnes previamente mastigadas pelos pais. Isso, dizem os Aikewara, é a base do seu desenvolvimento, tanto físico quanto moral: se a criança não estiver acostumada a consumir carnes, ela pode vir a não desenvolver - ou não desenvolver de maneira apropriada - características distintivas dos seres humanos, como andar sobre duas pernas e/ou cantar. E que o leitor tenha em mente que, nos termos propostos pela filosofia nativa, não se trata de um enunciado do tipo "nutricional", mas de uma modulação da vontade do feto; se trata menos da quantidade de carne consumida do que propriamente do "desejo" pela carne dos animais.

Poder-se-ia dizer algo semelhante a respeito dos sexos. Homens (aku$m a ’ e ̂)$ e mulheres (kusó) são aqueles que caminham enquanto tais, que percorrem o caminho próprio desse tipo de corpo. E isso, entre outras coisas, pressupóe uma modulaçáo adequada do seu desejo. Destarte, o próprio do corpo masculino seria o desejo pela carne das mulheres, o próprio do femi- 
nino, o desejo pela carne dos homens - lá, como aqui, muitas vezes o desejo sexual é expresso explicitamente por um vocabulário alimentar. Desejo que se manifesta publicamente - e em muito estimulado pelos adultos - ainda durante as brincadeiras infantis: não é raro encontrar crianças fazendo aquilo que os adultos denominam su'u-angaw ("sexo-por-engano"), isto é, imitando relaçóes sexuais, brincadeiras, estímulos. Essa, de fato, é uma das poucas ocasiôes em que meninos e meninas assumem papéis diferentes durante uma "brincadeira" - os meninos assumem a posição de ativos, as meninas de passivas -, pois o usual é que brinquem indistintamente juntos. Essas brincadeiras "acostumam", dizem os Aikewara, preparam os corpos de meninos e meninas para a prática sexual: eles amadurecem da maneira como se espera, o pênis dos meninos torna-se maior, duro, a vagina das meninas se alarga, torna-se penetrável, elas ganham seios, menstruam.

É mister notar que a despeito dos corpos serem "acostumados" a desejar e, portanto, a se movimentar conforme um certo padrão ainda nos primeiros momentos de sua existência, nada além de sua própria vontade os impede de se desviar desse caminho. Trata-se de um ponto fundamental, pois o apé de um vivente qualquer seria assim menos um destino imutável que uma trilha, como aquelas que lentamente, passo a passo, um caçador inscreve no interior da mata fechada, em busca de uma presa - e essa é a forma como o próprio Awassa'i me explicava o processo. Destarte, da mesma maneira que um caçador pode desistir de sua presa, da mesma maneira que este pode se desviar caso perceba a presença de outro animal nos arredores, um vivente pode se desviar do seu caminho por conta de uma mudança de interesses, uma mudança no seu desejo. E isso, esse desvio, ainda que momentâneo, tem para os Aikewara consequências profundas.

Afinal, se gente (awa) é aquele que caminha como tal - e isso, vimos, implica em desejar como tal -, o que acontece com aquele que deseja e caminha de maneira distinta? $\mathrm{O}$ que acontece, por exemplo, quando um homem passa a desejar como um, digamos, animal? O que acontece com um homem quando este passa a desejar como uma mulher?

Como vimos nos mitos, a resposta dos Aikewara a esse tipo de questionamento é, ao mesmo tempo, simples e complexa: simples pois determina de maneira pragmática que esse homem, sua existência, se aproximaria - por vezes perigosamente, como no caso dos animais - do "caminho" de outrem. Com efeito, pois a exemplo daquilo que se passou no mito, um homem que deseje e, portanto, se mova como um animal pode vir a se transformar em um; da mesma maneira que um homem que deseje e se mova como uma mulher pode vir a se transformar em uma. ${ }^{17}$ Contudo, a assertiva nativa assume ares mais complexos quando a levamos realmente a sério - e esse é, justamente, um dos pontos deste texto -, categorias como humano ou ani- 
mal, homem ou mulher, seriam, aos olhos do pensamento aikewara, menos coisas em si do que "estados", melhor, estágios de um movimento, "repousos temporários" da soma. Estágios que, segundo meus amigos, têm na origem um desejo. Isso posto, não é de se estranhar que, entre os Aikewara, existam homens-mulheres, ou, nos termos nativos, kusó-angaw.

De fato, se bem compreendo aquilo que me diziam meus amigos, da mesma maneira que todo humano é, ao menos em potência um animal (e vice-versa), todos os homens são também em parte mulheres. As kusó-angaw são justamente aquelas que, embora tenham nascido homens, que tenham sido feitas como tal, são portadoras de uma pulsão, de um desejo tipicamente feminino, e isso, por meio do comércio sexual, traz à tona a parte mulher de seus corpos. Em outras palavras, as kusó-angaw são estas que nasceram homens, mas que por uma razão ou outra optaram pelo caminho próprio das mulheres e, por meio desse passeio - a exemplo daquilo que se passou com o gäipymonómonó-tara -, tornam-se quase mulheres. ${ }^{18}$

Quando lhes inquiria sobre o que levava alguns homens a portar dentro de si esse "desejo destoante", meus amigos recorriam a teorias quase fenomenológicas. Na maioria dos casos, começa durante os sưu-angaw da infância, quando um menino se coloca, justamente, na posição de menina. Ele termina por se acostumar ao ato, à posição passiva da brincadeira e ao desejo por aqueles que até então eram seus semelhantes - da mesma maneira que os meninos se acostumam à posiçáo ativa e ao desejo pelas meninas. Mais do que isso, diz-se que tais brincadeiras dificilmente incluem a penetraçáo, "apenas sarram”, mas ainda assim são suficientes para que ele vá, pouco a pouco, madurando como se fosse uma menina. Com efeito, conforme "brinca", dizem, seu ânus vai se alargando - da mesma maneira que a vagina das meninas -, tornando-se gradativamente "penetrável". Mas isso não é tudo, durante a adolescência, esses/essas kusó-angaw não ganham corpo masculinos, não ganham músculos, permanecem magros, sua voz permanece fina e seu pênis nunca atinge as proporçóes daquilo que se espera do membro de um adulto. Sua identificação com as mulheres é tanta, sua proximidade com o caminho trilhado por estas é tamanha que, além das próprias, apenas as kusó-angaw são permitidas durantes suas cantorias. ${ }^{18}$

\section{O sentido do desejo}

Creio que a esta altura já não nos resta dúvida sobre o papel que os Aikewara atribuem ao desejo na produçáo dos corpos dos viventes. É mister salientar que este processo de produção se dá por meio de uma diferenciação. Vejamos o caso daqueles que tomam as kusóangaw como amantes, em 
geral outros jovens em vias de se tornarem adultos. Diz-se que ali, no sexo, a kusóangaw é verdadeiramente uma mulher para eles, e isso os tornam - coloquemos assim, na falta de uma palavra mais adequada - mais masculinos. Em outras palavras, esses rapazes maduram propriamente como homens na medida em que tomam os kusóangaw como mulheres. De fato, alguns dizem que tais relaçóes são ainda mais adequadas para o "caminho dos homens", pois o sexo anal - prática repudiada pela ampla maioria das mulheres aikewara - é visto como uma espécie de desafio para o pênis, um desafio maior do que a vagina, contribuindo, assim, para sua melhor formação, tornado-o maior, mais grosso, tornando a ereção masculina mais duradoura e rígida. Tornando-os, em suma, mais homens, tornando-os mais awaeté - e aqui, friso, estou reproduzindo o entendimento nativo.

Tudo se passa, então, como se estivéssemos, mais uma vez, diante dos esquemas relacionais do mito, como se estivéssemos observando os caminhos traçados pela seta do tukasására. Com efeito, aqui, como lá, a diferença emerge gradualmente entre estes que até então eram próximos: trata-se de homens separados pelo desejo, enquanto um deles caminha na direção do polo masculino, caminha propriamente como um homem, o outro caminha na direção do polo feminino, caminha propriamente como uma mulher. E são, justamente, essas partes que entram em contato durante o comércio sexual. Como nos mitos, o desejo opera um corte, um corte que antecede, inclusive, o movimento, o sexo. Explico: um dos axiomas fundamentais da filosofia aikewara - e, desconfio, de outros povos indígenas - é que o desejo é algo que se sente por outro, por algo que lhe é diferente: se desejo algo, esse algo náo pode ser "eu", ou algo próximo de mim. A diferenciação, a disjunção inclusiva que se observa no sexo, no fundo, é apenas uma manifestação observável de um processo anterior ainda mais profundo, o sentido do desejo.

\section{Notas}

1. Aikewara é a maneira como uma população, cerca de 360 indivíduos falantes de uma língua tupi-guarani, se autointitula. Sem cognatos conhecidos em línguas próximas (Parakaná, Assurini do Trocará), o termo costuma ser glosado pelos próprios como "gente daqui", em oposição àquilo que denominam aipewara, "gente de lá", estrangeiros.

2. Segundo Rodgers (2002), podemos encontrar noção semelhante no pensamento Ikpeng.

3. Por motivos de higiene textual, a partir deste momento deixarei de utilizar aspas para designar a noção de caminho. Que o leitor tenha em vista que ela, sempre que surgir, se remete a supracitada noção indígena de apé. 
4. Como bem diziam Deleuze e Guatarri: " $[\mathrm{O}]$ recurso ao mito é indispensável, não porque ele seja uma representação transposta ou mesmo invertida das relaçóes reais em extensão, mas porque apenas o mito determina conformemente ao pensamento e à prática indígenas as condiçôes intensivas do sistema (o sistema de produçáo inclusive)". (2010, p. 187)

5. "O não marcado da existência”, a cosmogonia aikewara, parece-me, leva essa noçáo ao extremo quando postula que - ao menos em seu momento inicial - nesse outro mundo sequer existiam "parentes" (-hysa). Os Aikewara são categóricos quanto a isto: apoiam-se na ideia de que nesse "outro tempo" - para nos utilizarmos de uma das designaçóes nativas do caosmos mítico - as pessoas já nasciam prontas, isto é, adultas. Explico: após uma relação sexual, as mulheres davam a luz de imediato; a criança, em poucos segundos, se transformava em adolescente e simplesmente "ia embora". Destarte, não havia tempo para consumar as relaçóes das quais o parentesco, segundo meus amigos, necessita para existir, isto é, não havia tempo para fazer dos outros "não outros", para transformar o "não marcado" em "marcado" (cf. LEPRI, 2003; 2005; ver também VIVEIROS DE CASTRO, 2002a; 2002b; 2007).

6. O "Espírito de Deus movia-se sobre a face das águas" (Gênesis, 1:2), assim meus amigos reconheciam o evento na bíblia.

7. Não é por coincidência que meus amigos descrevem o processo como parte de um "enrijecimento" contínuo do mundo, como parte de sua "maduração" corporal (semotówi, em sua própria língua). De fato, aos olhos da filosofia nativa, tudo se passa como se a própria existência fosse um corpo e, como tal, nasce "mole" (tawá) e leve e, pouco a pouco, se torna cada vez mais pesada.

8. Em nossas conversas, era comum que Awasải dispusesse espontaneamente seu acervo mitológico sobre uma única linha cronológica - embora ele nunca a contasse toda de uma única vez -, formando uma epopeia cujo início remete precisamente à narrativa acima. "Essa é a primeira", ele dizia. "Sem ela não haveria nada", acrescentava, "não haveria índio, não haveria kamará [branco], não haveria bicho, não haveria nada".

9. Noto que, nesse tempo, a humanidade se servia apenas da carne de jabutis - que náo eram lentos como os de hoje, corriam como se fossem cotias.

10. Como afirmei anteriormente, a cosmogonia aikewara encontra-se disposta ao longo de uma linha cronológica. A menarca da Cutia marca a emergência de uma temporalidade corporal entre os humanos, que agora já não maduravam de imediato, que tinham que esperar para crescer. A esse episódio soma-se uma outra narrativa na qual a Mucura, motivada pela inveja que sentia da vida sexual das outras jovens, as engana para que elas passem a "guardar" seus filhos em seus ventres, acabando, assim, o nascimento imediato. 
11. Com efeito, pois existem corpos e corpos, como me dizia o velho xamá, uns maiores e mais pesados do que outros, uns mais crescidos e madurados do que outros. Existem corpos mais ou menos capazes de operar cortes no fluxo da sociabilidade, mais ou menos capazes de produzir aquilo que a etnoantropologia nativa denomina como uma máekwera, uma "parte", em uma tradução literal. Uma espécie natural, por exemplo, seria assim uma "parte" em relação aos demais viventes, da mesma maneira que uma família extensa seria uma "parte" em relação aos demais Aikewara. "Partes" cuja existência encontra-se vinculada a um tipo de corpo muito específico, um corpo que, muito antes de ser replicado por cada um dos seus integrantes, teve que ser diferenciado dos demais, destacado do fluxo de sociabilidade. Um corpo que surgiu como resultado de um corte. Os queixadas, por exemplo, não surgiram todos de uma só vez, foi preciso que um primeiro, um hypia, se desviasse dos demais humanos, que este, que era um homem irascível, dizem, se mudasse para o meio do mato e passasse a morar em malocas de lama - no lugar das tradicionais malocas de palha. Foi preciso que esse homem cujo nome era Queixada se separasse dos demais humanos para que os queixadas de hoje, seus corpos, pudessem existir.

12. Proposição que nada tem de original, a tese de Garcia (2010) sobre os Guajá apresenta uma descrição minuciosa da "fome" e da dieta das flechas entre os Awa-Guajá.

13. Zona essa que se manifesta sobre a forma de sonhos: o caçador sonha com a caçada, mas agora preso à perspectiva de sua vítima; sonha com uma visita aos parentes da presa, durante a qual se oferece como cunhado.

14. Por questóes práticas, venho adotando a palavra "simulacro" como uma tradução temporária para o termo -angaw (cf. CALHEIROS, 2014). Contudo, inspirado pelo pensamento nativo, creio na necessidade de nos afastarmos desse vocabulário platônico; termos como "efeito" ou "fantasma" - em sua acepção estoica - me parecem, hoje, mais adequados.

15. Interessante notar como a figura do mito aikewara, um homem que morre ao tomar para si funçóes femininas por conta da incompletude de seu corpo, aproxima-se das narrativas de outros povos, como aquela que Wagley afirma ter escutado de Karamaiho, o seu principal interlocutor Tapirapé: "He made manioc flour, he cooked, he carried water, and he painted his body with genipap like a woman [...]. Karamaiho never saw this transvestite, but said that he remembers that older men had said that the 'man-woman' had died because she was pregnant. 'Her stomach was swollen but there is no womb to allow the child to be born'”. (WAGLEY, 1977, p. 160).

Lagrou, em seu estudo sobre os Kaxinawa, descreve algo muito semelhante, o passeio de um personagem mítico denominado Napu ainbu: um homem 
que sabia desenhar, tecer e cantar (artes femininas), que se pintava como mulher, se vestia como uma e agia de maneira conforme. Napu tinha um amante e dele engravidou. Morreu durante o parto da criança, pois não tinha uma vagina (2007, p. 194).

16. Ainda que, na maioria dos casos, essa transformação não se dê na mesma intensidade e velocidade que no mito. E que o leitor se lembre de que não há nada de exatamente novo nesse tipo de assertiva, a "feitura continuada" do corpo ameríndio, antes performado do que dado, são objetos da antropologia desde idos dos anos 1970 (cf. SEEGER et al., 1979).

17. Utilizo-me do artigo feminino para designá-las pois é assim que os próprios o fazem em bom português.

18. Diz-se que as músicas femininas são capazes de fazer o pênis de um homem cair.

\section{Referências bibliográficas}

CALHEIROS, Orlando. Aikewara: esboços de uma sociocosmologia tupi-guarani. Rio de Janeiro: Museu Nacional, 2014.

DELEUZE, Gilles; GUATARRI, Félix. $O$ anti-Édipo: capitalismo e esquizofrenia. São Paulo: Editora 34, 2010.

GARCIA, Uirá Felippe. Karawara: a caça e o mundo dos Awá-Guajá. São Paulo, 2010. Tese (Doutorado em Antropologia Social) - Faculdade de Filosofia, Letras e Ciências Humanas - Universidade de São Paulo.

GOLDMAN, Irving. The Mouth of Heaven: an introduction to Kwakiutl religious thought. Nova York: John Wiley, 1975.

LAGROU, Els. $A$ fluidez da forma: arte, alteridade e agência em uma sociedade amazônica (Kaxinawa, Acre). Rio de Janeiro: TopBooks, 2007.

LEPRI, Isabella. "We Are Not the True People" - notions of identity and otherness among the Ese Ejja of northern Bolivia. Londres, 2003. Tese (Doutorado) University of London.

Identidade e alteridade entre os Ese Ejja da Bolívia setentrional. Mana, Rio de Janeiro, v. 11, n. 2, out. 2005.

LIMA, Tânia Stolze. O dois e o seu múltiplo. Reflexôes sobre o perspectivismo em uma cosmologia tupi. Mana, Rio de Janeiro, v. 2(2), p. 21-47. 1996.

RODGERS, David. A soma anômala: a questão do suplemento no xamanismo e menstruação ikpeng. Mana [online], v. 8, n. 2, p. 91-125. 2002.

SEEGER, Anthony; DA MATTA, Roberto; VIVEIROS DE CASTRO, Eduardo. A construção da pessoa nas sociedades indígenas brasileiras. Boletim do Museu Nacional, 32, p. 2-19. 1979.

VIVEIROS DE CASTRO, Eduardo. Os pronomes cosmológicos e o perspectivismo ameríndio. Mana, v. 2(2), p. 115-144. 1996. 
O problema da afinidade na Amazônia. In: A inconstância da alma selvagem. São Paulo: Cosac Naify, 2002a.

Atualização e contra-efetuação do virtual: o processo do parentesco. In: A inconstância da alma selvagem. São Paulo: Cosac Naify, 2002aa.

Filiação intensiva e aliança demoníaca. Novos estudos - CEBRAP, São Paulo, n. 77, mar. 2007.

. Xamanismo transversal: Lévi-Strauss e a cosmopolítica amazônica. In: QUEIROZ, R. de C.; NOBRE, R. F. (Org.). Lévi-Strauss: leituras brasileiras. Belo Horizonte: Editora UFMG, 2008. p. 79-124.

WAGLEY, Charles. Lágrimas de boas vindas: os índios tapirapé do Brasil Central. Belo Horizonte: Itatiaia; São Paulo: Edusp (Reconquista do Brasil, 2. série, v. 137), 1988.

WAGNER, Roy. Lethal Speech: Daribi myth as symbolic obviation. Ithaca/Londres: Cornell University Press, 1978.

\section{autor Orlando Calheiros}

Doutor em Antropologia Social pelo Museu Nacional-UFRJ, especializado em etnologia indígena e filosofia moderna, atualmente é pós-doutorando do departamento de Filosofia da PUC-Rio, onde também atua como professor visitante.

Recebido em 10/12/2015

Aceito para publicaçáo em 10/12/2015 